\begin{tabular}{|c|c|c|}
\hline \multirow[t]{2}{*}{ 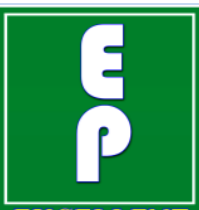 } & $\begin{array}{l}\text { International Journal of Current Research in } \\
\text { Biosciences and Plant Biology }\end{array}$ & \\
\hline & Volume $4 \bullet$ Number 8 (August-2017) • ISSN: 2349-8080 (Online) & \\
\hline $\begin{array}{l}\text { EXCELLEN } \\
\text { PUBLISHERS }\end{array}$ & Journal homepage: www.ijcrbp.com & 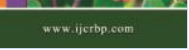 \\
\hline
\end{tabular}

\title{
Remote Sensing, GIS and Crop Simulation Models - A Review
}

\author{
K. Nagamani ${ }^{1}$ and V. E. Nethaji Mariappan ${ }^{2 *}$ \\ ${ }^{l}$ Scientist 'C' \& ${ }^{2}$ Scientist ' F', Center for Remote Sensing and Geo-Informatics, Sathyabama University, Rajiv Gandhi Road, \\ Sholinganallur, Chennai-600 119, Tamil Nadu, India
}

\section{*Corresponding author.}

\begin{abstract}
Agriculture continues to be the backbone of Third World economies. In India, more than two-thirds of population depends on agriculture. Agriculture provides the principal means of livelihood for over $58.4 \%$ of India's population. So the promotion of agriculture is an integral part of developmental programmes. The advances through information technology and space technology need to be extended to agriculture as well. Agriculture is always vulnerable, because of unfavorable weather and climatic conditions. So, it needs constant monitoring to improve crop productivity. The linkages among crop varieties, irrigation, soil characteristics, weather, etc., which are the key factors in agricultural productivity can be effectively made with the help of Remote Sensing and GIS tools. Crop Simulation Model (CSM) is a valuable tool to researchers to help them to understand the influence of climatic variables on crop productivity. Simulation models also provide global edge to the farmers and researchers since they are objective, fast and cost effective. The scope of applicability of these simulation models can be extended too much broader scales for regional planning and policy analysis by combining their capabilities with a Geographic Information System (GIS). The principle of this study appeal to review on Remote Sensing (RS), GIS and CSM, and on types of models and its limitations. Overview of CSM models in the current scenario, as well utilization of RS and GIS tools that model the impacts of agricultural interventions.
\end{abstract}

\section{Introduction}

India has made tremendous progress in agriculture and allied fields. Agriculture is always vulnerable to unfavorable climatic conditions. Agricultural productivity is mainly based on soil characteristics, climate and techniques of cultivation. There is an urgent need for systematic inventorying, mapping and monitoring of land resources for sustainable agricultural production. Crop simulation models (CSMs) are mathematical, computer-based representations of crop

\section{Article Info}

Accepted: 26 July 2017

Available Online: 06 August 2017

\section{Keywords}

Agriculture

Remote Sensing

Geographic Information System (GIS)

Crop Simulation Models (CSM) 
etc.) appeared in the early 1980s (e.g.: Wilkerson et al., 1983; Swaney et al., 1983). On farm applications of models were also reported (e.g. Lindemann et al., 1987; McKinion et al., 1988). Models such as SUCROS and others associated with the 'School of de Wit' (Bouman et al., 1996) as well as those of the CERES (Ritchie et al., 1998) and CROPGRO (Boote et al., 1998) families of models had a significant impact on the crop modeling community. These objectives can be effectively achieved with the help of tools such as Remote Sensing and Geographic Information Systems (GIS).

\section{Remote sensing}

Remote Sensing provides a source of data as well as the capacity for data processing and analysis, assessment, monitoring and forecasting tasks. Satellite Remote Sensing represents a technology for synoptic acquisition of spatial data and the extraction of scene using satellites. A discussion of the Remote Sensing technology would not be complete without the mention of GIS. Remote Sensing in India is reasonably well developed but not so are GIS applications. GIS is an evolving technology that has now reached certain maturity in the application areas. The indigenous technical knowledge with the help of Remote Sensing and GIS provides valuable insight into sustainable agriculture. An accurate spatial (and temporal) database enables the characterization of agro-systems. This paper discusses some Remote Sensing and GIS applications in agriculture.

\section{Change detection study}

Remote Sensing and GIS technology is now being applied to areas of agriculture. California developed an agricultural and environmental information system to study the vineyard expansion by integrating spatial information on agricultural areas with other information about the landscape such as topography, hydrography and vegetation (Adina, 2000). This inter-linkage allows the system to determine which watersheds may be disproportionately affected by vineyard development. In 1996, the Integrated Hardwood Range Management Programme established a GIS lab at the UC Hopland Research and Extension Centre. They used a GIS to integrate a map of Sonoma County's vineyards with other digital information.

Change detection of Land use / Land cover analysis of the semi-urban area was carried out using temporal multi-spectral data (1991 and 2001) of the LANDSAT TM images, systematically assessed, and checked in field through Remote sensing software for Vellore district in Tamil Nadu, India. . Initially 18 major classes were observed for both the images. To minimize similar features, relevant classes were reorganized to end up with 8 classes. The overall accuracy for a 1991 image is $78 \%$ and for a 2001 image is $80 \%$. The results demonstrate that the study area experienced a rapid, decrease in forest cover, conversion of wetland vegetation to barren / dry farming, rural to urban conversion in town and municipalities resulting in decreasing ground water table in the 10 year period between 1991 and 2001 (Nethaji Mariappan et al., 2010).

Chlorophyll does not absorb all wavelengths of sunlight; it absorbs the blue (Blue) and red (Red) wavelengths, while green (Green) light is reflected (Cambpell, 1996). The reflection of visible radiation is mainly function of leaf pigments, whereas the Near-Infrared (NIR) is reflected by the internal mesophyll structure of leaves. NIR radiation passes through the first layer of the leaf (the palisade tissue); when it reaches the mesophyll and the internal leaf cavities it is scattered both upwards (which is referred as reflected radiation) and downwards (transmitted radiation). The relative decrease in reflectance is higher in the visible spectrum than in the NIR, because of the effects of the transmittance of the NIR through the leaves and the absorption of red and blue from the chlorophyll pigment. The visible light is absorbed or reflected by the first leaf layers, while the NIR is transmitted downwards and reflected upwards partly from the soil and partly during its passage through the canopy. These two reflected NIR wavelengths may be detected by a sensor positioned above the crop. As a result of the above mechanism, healthy crops will show high values of reflectance in the NIR and low values in the visible spectrum.

\section{Vegetation indices}

Vegetation indices (VIs) are mathematical combinations or ratios of mainly red, green and infrared spectral bands; they are designed to find functional relationships between crop characteristics and remote sensing observations (Wiegand et al., 1990). Vegetation indices are strongly modulated by the interaction of solar radiation with crop photosynthesis and thus are indicative of the dynamics of biophysical properties related to crop status. 
Remote Sensing, GIS and GPS plays a vital component in monitoring vineyard cultivation in a near real time manner for delivering appropriate management inputs. A crux of vineyard distribution according to climatic conditions and consequence of adverse climatic conditions on production of vine is dealt without ambiguity. Role of remote sensing (optical and hyperspectral) on vineyard distribution, discrimination by various techniques, deriving both biophysical and biochemical variables from satellite images and monitoring of vine at various growth stages has been reviewed extensively (Nethaji Mariappan et al., 2017).

\section{Digital image processing}

The digital vineyard maps used for this project, which were originally compiled was put into digital format. It helped production of high-quality maps for tourists and wine enthusiasts. Vineyards were identified in Sonoma County using 1990 aerial photographs, and more recent vineyard developments were mapped from information provided by the grape growers themselves through 1977. Other digital information that was collected by various departments include elevation, slope and aspect data derived from the U.S. Geological Survey Digital Elevation Models (DEM); roads and streams from the U.S. Bureau; farmland and urban areas from the California Development of Conservation Farmland Mapping and Monitoring Programme; and vegetation from the California Department of Forestry and Fire Protection 1990 hardwoods layer. Additional base layers were also obtained from the Sonoma County Information Systems Department GIS Division. The various themes, which have been collected by them were integrated by GIS, and were intersected with maps showing the location of vineyards development before and after 1990 with elevation and slope derived from DEM.

Then they also used this GIS to extract all the variables in the vineyard expansion model. Areas suitable for vineyard expansion were identified using Remote Sensing and GIS. These technologies were used to map and monitor crop areas. Moving toward a single agricultural crop across the north coast is at odds with the principles of sustainable agriculture, and could lead to over-reliance on a single industry. Proponents of sustainable agriculture promote increasing biodiversity in conventional farming systems to reduce the use of insecticides, fungicides, herbicides and fertilizers (Bugg and Pickett, 1998). More information on soils, climate, geology and water would also be of great benefit in analysing vineyards development patterns. Higher resolution topographic information is becoming available and will improve our analysis capabilities. Recent developments in computer-aided technology and mapping analysis software have made it possible for more researchers to model land use change across large geographic regions (Goodchild et al., 1996).

\section{Geographic information system}

Globally, GIS is applied to disciplines ranging from managing utility networks to health, archaeology and ecology. Increasingly, it is a common component of climate change assessments. The geographic aspect of GIS makes it an interesting option for application to agricultural problems and priority setting because so many of the environmental and socio-economic factors that impact agriculture or agricultural research vary greatly over regions (e.g.: Benson, 1996). Typical examples would include rainfall patterns, soil variability, disease and pest distribution, market locations, crop distributions, land-use patterns and human demographics.

GIS is a computer mapping and analysis tool that allows the integration of large amounts of spatial and nonspatial information. It provides a digitized, spatiallyoriented database for evaluating the information along with other spatially-formatted data and information that may be acquired from satellites, maps, surveys and other sources of geo-referenced information (that which has a latitude and longitude). It enables digital overlays of different datasets, their joint spatial analysis and generation of user-required cartographic and statistical product from integrated databases. GIS can store a lot of spatial data and easily display how changes in natural resources or policies affect much of the region visually.

GIS is the way solution in assessing spatial mapping of air pollution is a serious problem in Industrial, Residential and Mixed places of the developing countries and especially Tamil Nadu in India. Due to increasing industrial development, the Tamil Nadu state particularly unban region like Chennai, Coimbatore, Tuticorin is subjected to subsequent air pollution problem. An appropriate spatial and temporal assessment is need of the hour to assess the spate of environmental pollution on human health. This study attempts to spatially and temporally explore the pollution concentration and assess with respect to Air 
Quality Index (AQI) of the available data on thermal power stations in Tamil Nadu. A comparison between the vehicular pollution concentrations and thermal pollution concentration has entailed us that $\mathrm{SO} 2$ and NOX emission was higher from vehicles and SPM was higher from thermal stations and that lead us to take precautionary measures in managing the environmental pollution (Nethaji Mariappan et al., 2013). This GIS holds promise of being a powerful tool of analysis and improvements can be thought of as to detect land use changes, quantify the environmental consequences and provide policy and planning analysis.

\section{Crop simulation models}

Crop Simulation Models (CSM) are computerized representations of crop growth, development and yield, simulated through mathematical equations as functions of soil conditions, weather and management practices (Hogenboom et al., 2004). The strength of the CSM is in their ability to extrapolate the temporal patterns of crop growth and yield beyond a single experimental site. Crop Simulation Models (CSM) can be used to gain new scientific knowledge of crop physiological processes or to evaluate the impact of agronomic practices on farmers' incomes and environments. Crop models are only an approximation of the real world and many do not account for important factors such as weeds, diseases, insects, tillage and phosphorus (Jones et al., 2001).

The purpose a crop model is to be used determines to a large extent the complexity of a model. Simple models are often used for yield estimation across large land areas based on statistical information related to climate and historical yields and include little detail about the soil-plant system. More complex mechanistic models may provide detailed explanations of the soil-plantatmosphere system and require a large amount of input data, some of which may not be available.

The use of crop models and their application in the agricultural field started in the 1970s, but different types of models are increasingly accessible for practitioners with different levels of exposure and expertise (Cheeroo-Nayamuth, 2001). The most commonly used models are the Environmental Policy Integrated Climate (EPIC) model (Williams, 1990), Decision Support System for Agro-Technology Transfer (DSSAT) model (Jones et al., 2003; Jones et al., 1998; Ritchie et al., 1985), and CROPWAT model (Smith, 1992). In most cases, the models have been developed for specific localities and are not always applicable for other regions (Adejuwon, 2005).

\section{Types of models}

Depending upon the purpose for which it is designed the models are classified into different groups or types. They are:

\section{Statistical models}

These models express the relationship between yield or yield components and weather parameters. In these models relationships are measured in a system using statistical techniques. Average yields from large areas (counties or crop reporting districts) and for many years were regressed on time to reveal a general trend in crop yields. When simulating yield using statistical models, the effects of changes in agricultural technology have to be subjectively extrapolated into time when the mix of the technology is unknown for that period. Hence a principal problem associated with statistical crop models is that the yield simulations may be made outside the range of weather and technology information from which the model was developed. Statistical models can provide many insights about past yields and historical influences and can be used to inform the other kinds of models.

\section{Mechanistic models}

These models explain not only the relationship between weather parameters and yield, but also the mechanism of these models is based on physical selection. These models have the ability to mimic relevant physical, chemical or biological processes and to describe how and why a particular response occurs. The modeller usually starts with some empirism and as knowledge is gained additional parameters and variables are introduced to explain crop yield. Mechanistic models usually describe instantaneous rates of plant processes that change rapidly over short time scales. For example, photosynthetic and transpiration processes change rapidly during the day as the radiation and temperature conditions change. A relatively large amount of input information is required to run such a model (Basso et al., 2013, www.fao.org).

\section{Deterministic models}

A deterministic model is one that makes definite 
predictions for quantities (e.g. crop yield or rainfall) without any associated probability distribution, variance, or random element. However, variations due to inaccuracies in recorded data and to heterogeneity in the material being dealt with are inherent to biological and agricultural systems (Brockington, 1979) these models estimate the exact value of the yield or dependent variable and also have defined coefficients.

\section{Stochastic models}

A probability element is attached to each output. For each set of inputs different outputs are given along with probabilities that give an expected mean value as well as the associated variance. These models define yield or state of dependent variable at a given rate. Stochastic models tend to be technically difficult to handle and can quickly become complex (Patricia Oteng-Darko et al., 2013)

\section{Static and dynamic models}

Time is included as a variable. Both dependent and independent variables are having values which remain constant over a given period of time expressed as differential equations. Time is not included as variables. Dependent and independent variables having values remain constant over a given period of time even if the end products of cropping systems are accumulated over time.

\section{Simulation models}

Computer models, in general, are a mathematical representation of a real world system. One of the main goals of crop simulation models is to estimate agricultural production as a function of weather and soil conditions as well as crop management. These models use one or more sets of differential equations, and calculate both rate and state variables over time, normally from planting until harvest maturity or final harvest (Murthy, 2004). They are designed to mimic the system at short time intervals (daily time-step), the aspect of variability related to daily change in weather and soil conditions is integrated. The short simulation time-step demands that a large amount of input data (climate parameters, soil characteristics and crop parameters), available for the model to run. These models usually offer the possibility of specifying management options and they can be used to investigate a wide range of management strategies at low costs.
The simplest models estimate daily growth through conversion factors for intercepted solar radiation to biomass, whereas complex models may simulate growth at a timescale of minutes and include routines to simulate key biochemical pathways of photosynthesis. Hay and Porter (2006) provide a general review of the physiological processes described in models, and Tsuji et al. (1998) describe multiple aspects of models, including soil and weather processes and example applications.

Crop simulation models are valuable tools to researchers to help them to understand the influence of climatic variables on crop productivity. A comprehensive GISbased biophysical crop simulation model, Spatial-EPIC, was used to demonstrate the crop growth response to the combined effects of increased $\mathrm{CO}_{2}$ concentration and $\mathrm{CO}_{2}$-induced climatic change at the national level in Bangladesh (Ahmed and Shibasaki, 2000). Modelling within a GIS environment offers a mechanism to integrate the data developed in different scales in agricultural research. The rice and wheat cropping system in Bangladesh is analysed for this purpose.

\section{Overview of crop simulation models}

\section{CROPWAT}

Smith (1991) developed the CROPWAT to evaluate the crop water requirements for rice and upland crops. The CROPWAT model was originally develop by the FAO in 1990 for planning and management of irrigation projects. CROPWAT is meant as a practical tool to carry out standard calculations for reference evapotranspiration, crop water requirements and crop irrigation requirements, and more specifically the design and management of irrigation schemes. It allows the development of recommendations for improved irrigation practices, the planning of irrigation schedules under varying water supply conditions, and the assessment of production under rain fed conditions or deficit irrigation.

\section{EPIC}

Environmental Policy Integrated Climate (EPIC) model (Williams, 1990) (Fig. 1) Traditional decision support system based on crop simulation models is normally site-specific. To address the effects of spatial variability of soil conditions and weather variables on crop production from one region to other, GIS is linked with 
biophysical agricultural management simulation model EPIC, which is known as Spatial-EPIC. This model can be applied to any size of agro-system starting from a field to a country and even a bigger area can be modelled. Spatial-EPIC system's file structure comprises text files, which contain estimate of parameters of different physical processes modelled by Spatial-EPIC. These files include basic user-supplied data file, crop parameter file, tillage parameter file, pesticide parameter file and daily weather data file. ArcView 3.1 is used as a pre- and post-processor for data furnishing as well as graphical display of SpatialEPIC.

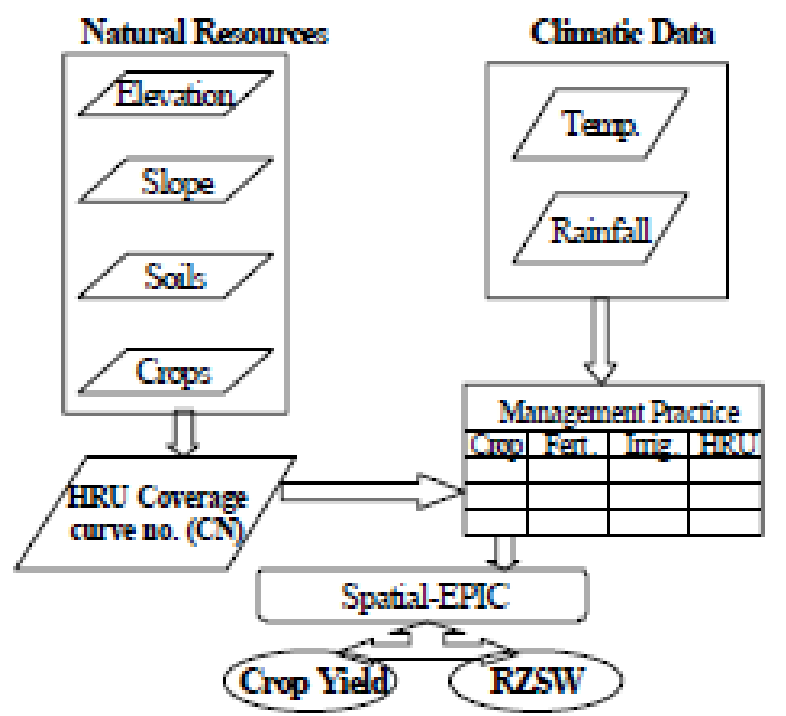

Fig. 1: A diagram to illustrate the interaction between natural resources, climatic data integrated to crop management file of Spatial EPIC Model.

Some of the Spatial-EPIC sub-models are soil, weather, plant environment and crop growth. In brief, the each sub-model is dealt with their computation procedure. The soil temperature sub-model responds to weather, soil water content and bulk density. It is computed daily in each soil layer. The crop growth sub-model is a single crop model capable of simulating major agronomic crops. Crop-specific parameters are available for most crops. The submodel also simulates crop grown in complete rotations. The plant environment sub-model is capable of a variety of cropping variables, management practices and other naturally occurring processes. These include different crop characteristics such as plant population and dates of planting and harvesting, fertilization, irrigation, and many more of those normally practiced in the field.

\section{SALUS model}

Another successful application of web-based simple interface crop simulation model is the SALUS model as described by Basso et al. (2012, 2010) (www.salusmodel.net). The model is designed to be used by farmers or extension specialists to quantify the impact of management, soil and weather interaction on yield and environmental impact.

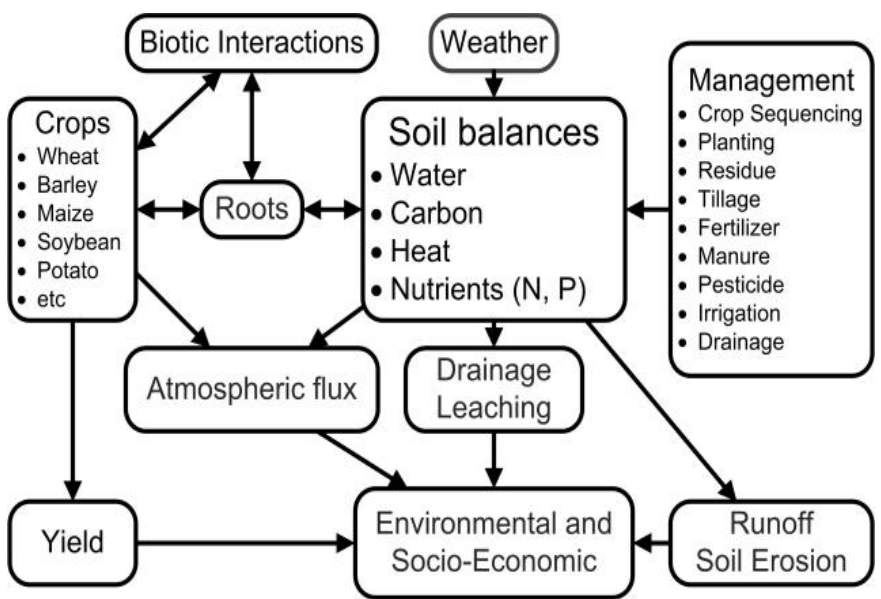

Fig. 2: A diagram to illustrate the interaction between soilplant-atmosphere as accounted in the SALUS model (www.salusmodel.net)

The SALUS (System Approach to Land Use Sustainability) model (Fig. 2) is an ongoing team effort started by Joe Ritchie at Michigan State University in late nineties and currently carried on by Bruno Basso (Basso et al., 2007; Basso et al., 2010). SALUS is similar in detail to the DSSAT family of models but is designed to simulate crop yield in rotation, soil, water and nutrient dynamic as function of management strategies for multiple years. The SALUS program is designed to simulate continuous crop, soil, water and nutrient conditions under different management strategies for multiple years, taking into account several aspects such as crop rotations, planting dates, plant populations, irrigation and fertilizer applications, and tillage regimes (Dzotsi et al., 2013).

i-Salus is also a web-based agronomic decision support system. i-Salus is composed by two interfaces: a simple interface and Web-GIS interface. SALUS with the simple interface is a user friendly system $\mathrm{s}$ targets at farmers or extension specialists who can simulate the impact of different management strategies on yield, and environmental impact. SALUS-WebGIS is a web-based GIS integrated with Google Earth and Salus model to 
simulate in a spatial explicit manner the effect of climate-soil-genotype-management interaction on crop yield and environmental impact.

\section{APSIM model}

Agricultural Production Systems Simulator (APSIM) is a modelling framework that allows individual modules of key components of the farming system (defined by model developer and selected by model user) to be 'plugged in' (McCown et al., 1996). In this regard, it shares somewhat common objectives with APSIM (McCown et al., 1996; Keating et al., 2003), a modeling approach that has evolved to place substantial resources in the development of quality software engineering practices.

The Agricultural Production Systems Simulator (APSIM) is a modular modelling framework that has been developed by the Agricultural Production Systems Research Unit in Australia. APSIM was developed to simulate biophysical process in farming systems, in particular where there is interest in the economic and ecological outcomes of management practice in the face of climatic risk (Yunusa et al, 2004). APSIM's structure and provides details of the concepts behind the different plant, soil and management modules. These modules include a diverse range of crops, pastures and trees, soil processes including water balance, $\mathrm{N}$ and $\mathrm{P}$ transformations, soil $\mathrm{pH}$, erosion and a full range of management controls. Reports of APSIM testing in a diverse range of systems and environments are summarized. An example of model performance in a long-term cropping systems trial is provided. APSIM has been used in a broad range of applications, including support for on-farm decision making, farming systems design for production or resource management objectives, assessment of the value of seasonal climate forecasting, analysis of supply chain issues in agribusiness activities, development of waste management guidelines, risk assessment for government policy making and as a guide to research and education activity. An extensive citation list for these model testing and application studies is provided (Keating et al., 2003).

The APSIM modelling framework is made up of; a) a set of biophysical modules that simulate biological and physical processes in farming systems, b) a set of management modules that allow the user to specify the intended management rules that characterise the scenario being simulated and that control the conduct of the simulation, c) various modules to facilitate data input and output to and from the simulation, and d) a simulation engine that drives the simulation process and controls all messages passing between the independent modules.

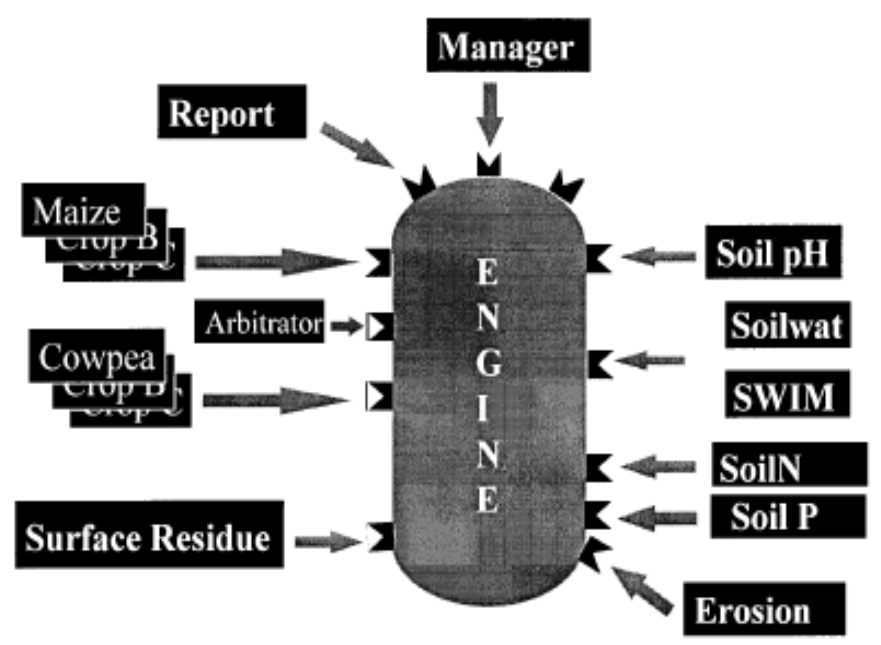

Fig. 3: Spider Diagram of APSIM framework.

These elements of the APSIM framework have been illustrated by the 'spider diagram' (Fig. 3), which more correctly represents a 'hub and spokes' metaphor. Framework in this context refers to a set of structures that support the higher order goal of farming systems simulation.

\section{CropSyst}

CropSyst is a multi-year, multi-crop, daily time step cropping systems simulation model developed to serve as an analytical tool to study the effect of climate, soils, and management on cropping systems productivity and the environment. CropSyst simulates the soil water budget, soil plant nitrogen budget, crop phenology, canopy and root growth, biomass production, crop yield, residue production and decomposition, soil erosion by water, and salinity.

The main components of the CropSyst Suite are: CropSyst parameter editor, a cropping systems simulator (CropSyst model), a weather generator (ClimGen), a GIS-CropSyst simulation co-operator (ArcCS), a watershed analysis tool (CropSyst Watershed), and several utility programs.

The cropping systems simulator is the core of the suite of programs. It contains all the necessary objects, 
procedures, and functions to simulate the productivity of crops and crop rotations in response to weather, soil and management. The model simulates a single land block fragment. A land block fragment represents a biophysically homogeneous unit area with a uniform management regimen. Simulation scenarios for land block fragments are created by preparing parameter files describing the climate, soil, crops and crop management. A simulation control file identifies and links all the input files, provides initial conditions, selects optional simulation modules, and specifies the scenario to be simulated (Fig. 4).

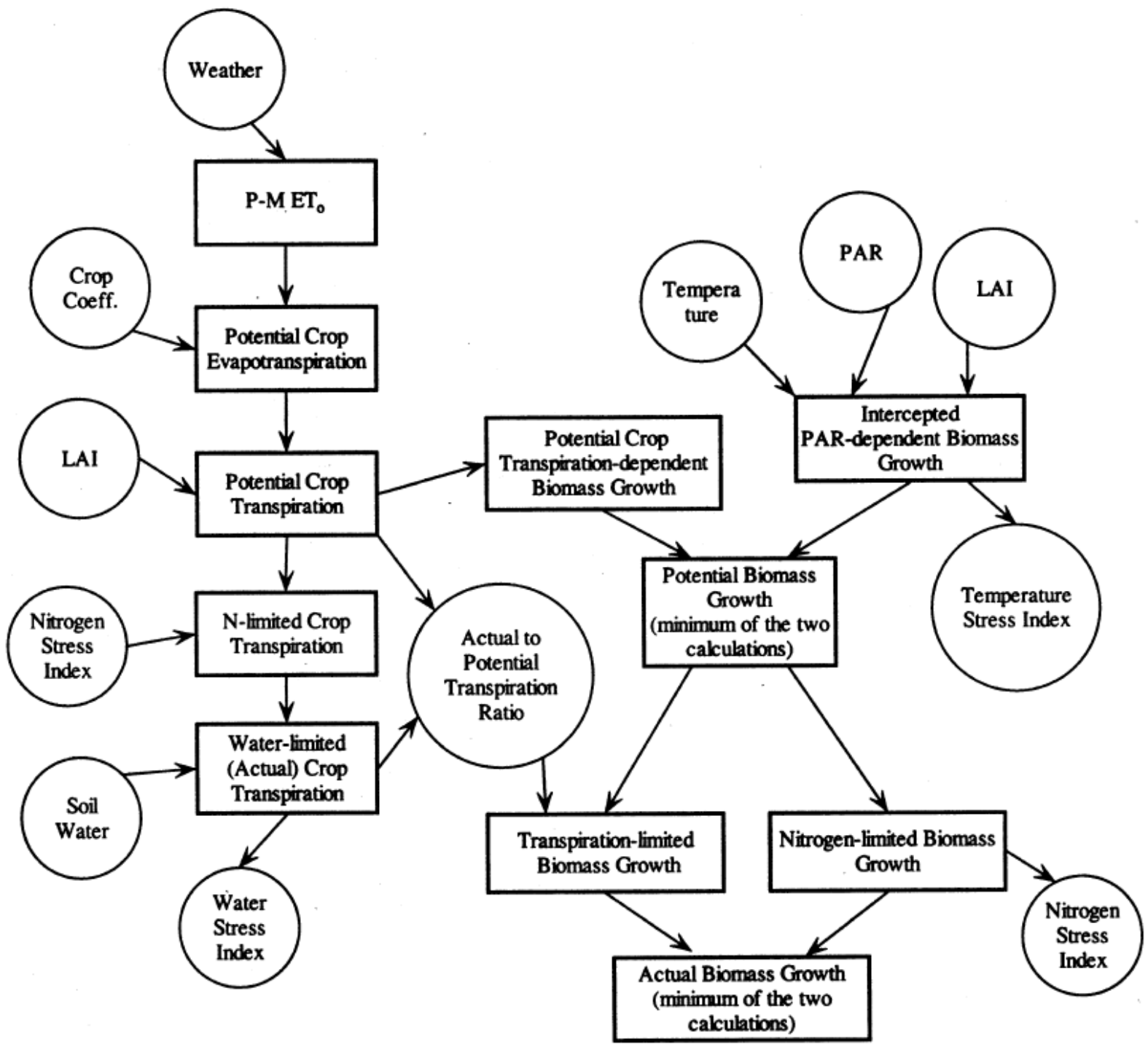

Fig. 4: Flow chart of CropSyst model.

\section{DSSAT models}

IBSNAT (International Benchmark Sites Network for Agrotechnology Transfer) began the development of a model in 1982. IBSNAT was an attempt to demonstrate the effectiveness of understanding options through systems analysis and simulation for ultimate benefit of farm households across the globe. The purposes defined for the IBSNAT project by its technical advisory committee were to understand ecosystem processes and mechanisms, synthesize from an understanding of processes and mechanisms, a capacity to predict outcomes and enable IBSNAT clientele to apply the predictive capability to control outcomes. Decision Support System for Agro- Technology Transfer (DSSAT) which is currently being used as a research and teaching tool was developed by IBSNAT.

Decision Support System for Agro-Technology Transfer (DSSAT) model (Jones et al., 2003; Jones et al., 1998; 
Ritchie et al., 1985). The DSSAT model is a software application program that comprises crop simulation models for over $28 \mathrm{crops}$, models which include the CERES models for cereals (barley, maize, sorghum, millet, rice and wheat); the CROPGRO models for legumes (dry bean, soybean, peanut and chickpea); and models for root crops (cassava, potato) and other crops (sugarcane, tomato, sunflower and pasture) and is used to simulate growth, development and yield as a function of the soil-plant-atmosphere dynamics (DSSAT.net, 2013). Applications cover over 100 countries worldwide with a history of more than 20 years (DSSAT.net, 2013).

DSSAT products enable users to match the biological requirements of crops to the physical characteristics of land to provide them with management options for improved land use planning. The package consists of: data base management system for soil, weather, genetic coefficients, and management inputs, Crop simulation models, series of utility and weather generation programs and strategy evaluation program to evaluate options including choice of variety, planting date, plant population density, row spacing, soil type, irrigation, fertilizer application, initial conditions on yields, water stress in the vegetative or reproductive stages of development, and net returns.

\section{Applications of crop simulation models}

The EPIC, ALAMANC, CROPSYST, WOFOST, ADEL models are being successfully used to simulate maize crop growth and yield. The most common growth models used in application for cotton are the GOSSYM (Mckinion et al., 1989) and COTONS models. On the same analogy the PNUTGRO (Boote et al., 1989) for groundnut, CHIKPGRO for chick pea, WTGROWS for wheat, SOYGRO for soybean, BEANGRO (Hogenboom et al., 1994) for beans QSUN for sunflower are in use simulating crop growth on spatial domain. SorModel, SORGF as also ALMANAC models are being used to address specific tasks of sorghum crop management. CERES - pearl millet model, CROPSYST, PmModels are being used to study the suitability and yield simulation of pearl millet genotypes across the globe.

Hammer et al. (1995) using local weather and soil information correlated peanut yields with estimates from PEANUTGRO, a model in the CERES family and gave a regression with high coefficient $\left(\mathrm{r}^{2}=0.93\right)$ of variation. The construction of contemporary crop models entails the combination of many algorithms for physiological processes and impact of environmental factors on process rates (Monteith, 2000). Hilger et al. (2000) examined the potential of the EPIC model by coupling it with the Agricultural Land Management Alternatives with Numerical Assessment Criteria (ALMANAC) model to estimate crop yields under erratic rainfall in northeast Brazil. The objective of their study was to examine the potential of both models to simulate growth and yield performance of annual crops under these conditions. The structures of both models are appropriate for simulating crop production. However, both models partly failed to simulate crop growth and yield performance with increased planting density and input uses on less favorable sites.

Kapetanaki and Rosenzweig (1997) applied a simulation study with CERES-Maize to show the impact of climate change on maize yield in central and northern Greece. Climate change scenarios were developed by doubling the $\mathrm{CO} 2$ from three general circulation models (GCMs). A consistent increase in air temperature, small increases in solar radiation and precipitation changes were added to these scenarios. The study results showed that the maize yield would likely decrease under present management practices, due to the reduced duration of the growing period at all sites. The effects of micro nutrients on crop yields by applying the DSSAT model are found in different studies. Sarkar and Kar (2006) conducted a simulation study in West Bengal, India from 2001 to 2003 using the seasonal analysis program of the Decision Support Systems for Agro-technology Transfer (DSSAT 3.5) suite of models.

Nazeer (2009) used a simulation of maize under irrigated and rain-fed conditions with the CROPWAT model. The field experimental data of maize was collected from the Mardan district of the NWFP, Pakistan, and used as an input in the CROPWAT model. The study results suggest that the application of adequate irrigation scheduling can markedly reduce the yield losses. CROPWAT model has been found useful for showing the effects of climate change on crop yields and optimal water use (Antonellini et al., 2014; Blanc et al., 2013).

As a result of long term exploration, an interdisciplinary field of information on associations between the geophysical environment and plant productivity has developed quantitative theory, following the template of such traditional mathematically based disciplines as hydrology and meteorology. Now the agro ecosystem is 
considered a dynamically developing open system - a green machine that absorbs solar radiation. $\mathrm{CO}_{2}$, and other necessary substrates from the environment and produces organic substances. A system of differential equations and boundary conditions describing the green machine has been developed, and integration of this system of equations allows calculation of agro ecosystem productivity, depending on conditions in the physical environment at its boundaries. Thus, the problem of calculating agro ecosystem productivity is formulated as boundary value problem of mathematical physics. All known crop simulation models can be treated as simplifications of this basic control system (Sirotenko, 1996). The development of a theory is equivalent to possession of a network of good roads through which any advances in different fields can be easily built into a common system of equations and used to solve the principal problem is nothing but calculation the agro ecosystem productivity.

\section{Conclusion}

This research reviewed a Remote Sensing and GIS applications in agriculture, with specific reference to Crop Simulation Models. Range of decision-making tools, user-end research models, and evaluation methods used to assess the potential impacts of agricultural technology in developing countries. The tools and approaches reviewed here vary considerably by complexity, function, and intended use.

Change detection of cropping pattern over a period of time can be successfully studied. GIS can help planners and decision makers to supervise and correct agricultural reforms according to the adopted strategy - as GIS aided by inputs from satellite imagery provides much-needed objective and updated information. Models can be can be suitably used for simulating sub module viz., soil moisture, irrigation management, crop rotation, water productivity, yield prediction of any region in the world. Thus models help decision makers to respond scientifically to a changing agricultural situation.

A few other applications in agriculture that can be predicted trough crop simulation models are are: (i) flood monitoring which also includes analyzing the extent of crop damage; (ii) studying the extent of crop damage due to drought; (iii) the prediction of rice or wheat produce by analyzing the health of crops which can help plan marketing strategy; (iv) to determine the agricultural pattern suitable for a particular terrain; (v) mapping of degraded soils; (vii) monitoring of encroachments of lands earmarked for agriculture; (ix) meteorological information such as rainfall forecast.

Higher resolution satellite data is becoming available and will improve analysis capabilities. Thus Remote Sensing and GIS applications can help the decision makers in agriculture in a variety of ways. The descriptions provided in this document give a broad view of the types of models and tools that are available to analyze the impact of agricultural interventions.

\section{Conflict of interest statement}

Authors declare that they have no conflict of interest.

\section{Acknowledgement}

Authors thank the management of Sathyabama University for their moral support and infrastructural facilities for conducting review in our capacity. The authors thank the Scientist of Centre for Remote Sensing and Geoinformatics, scholar, Sathyabama University, Chennai for immensely supported for preparation of this manuscript. The authors thank the anonymous reviewers for their insightful comments and suggestions.

\section{References}

Adejuwon, J., 2005. Assessing the suitability of the EPIC crop model for use in the study of impacts of climate variability and climate change in West Africa. Singapore J. Trop. Geogr. 26(1), 44-60.

Adina, M., 2000. Mapping vineyard expansion provides information on agriculture and the environment. California Agric. 54(3), 7-20.

Ahmed, A., Shibasaki, R., 2000. Climate Change and Agricultural Food Production of Bangladesh: An Impact Assessment Using GIS-based Biophysical Crop Simulation Model. http://www.gisdevelopment. net/aars/acrs/2000/ts1/agri004pf.htm.

Antonellini, M., Dentinho, T., Khattabi, A., Masson, E., Mollema, P., Silva, V., Silveira, P., 2014. An integrated methodology to assess future water resources under land use and climate change: An application to the Tahadart drainage basin (Morocco). Environ. Earth Sci. 71(4), 1839-1853.

Arkin, G.F., Vanderlip, R.L., Ritchie, J.T., 1976. A dynamic grain sorghum growth model. Trans. ASAE. 19, 622-626, 630.

Basso, B., Cammarano, D., Troccoli, A., Chen, D., 
Ritchie, J.T., 2010. Long-term wheat response to nitrogen in a rainfed Mediterranean environment: Field data and simulation analysis. Eur. J. Agron. 33, 132-138.

Basso, B., Chou, T.Y., Chen, C., Yeh, M., 2012. i-Salus: New web based spatial systems for simulating crop yield and environmental impact. Proc. Inter. Conf. Precision Agriculture Indianapolis.

Basso, B., Cammarano, D., Carfagna, E., 2013. Review of Crop Yield Forecasting Methods and Early Warning Systems. http://www.fao.org/fileadmin/ templates/ess/documents/meetings_and_workshops/ GS_SAC_2013/Improving_methods_for_crops_ estimates/Crop_Yield_Forecasting_Methods_and_E arly_Warning_Systems_Lit_review.pdf.

Basso, B., McVicar, T.R., Lee, B., 2007. Remote sensing and GIS applications in agrometeorology. In: Chapter 12: Guidelines of Agrometeorological Practices (Ed.: Stitger, K.). World Meteorological Organization of the United Nation. Geneva. Switzerland.

Benson, T., 1996. The Use of Geographic Information Systems in Agricultural Research in Malawi. SoilFertNet Network Methods Working Paper 1. International Maize and Wheat Improvement Center (CIMMYT), Mexico, DF.

Blanc, E., Strzepek, K., Schlosser, C. A., Jacoby, H. D., Gueneau, A., Fant, C., Reilly, J. M., 2013. Analysis of US Water Resources under Climate Change.Massachusetts: MIT Joint Program on the Science and Policy of Global Change.

Boote, K.J., Jones, J.W., Hoogenboom, G., Wilkerson, G.G., Jagtap, S.S., 1989. PNUTGRO VI.0, Peanut crop growth simulation model, user's guide. Florida Agric. Exp. Station J., 8420, 1-83. University of Florida, Gainesville, Florida, USA.

Boote, K.J., Jones, J.W., Hoogenboom, G., Pickering, N.B., 1998. The CROPGRO model for grain legumes. In: Understanding Options for Agricultural Production (Eds.: Tsuji, G.Y., Hoogenboom, G., Thornton, P.K.). Kluwer Academic Publishers, Dordrecht, The Netherlands. pp.99-128.

Bouman, B.A.M., van Keulen, H., van Laar, H.H., Rabbinge, R., 1996. The 'School of de Wit' crop growth simulation models: A pedigree and historical overview. Agric. Syst. 52(2), 171-198.

Brockington, N.R., 1979. Computer Modeling in Agriculture. Clarendon Press, New York. 156p.

Bugg, R.L., Pickett, C.H., 1998. Enhancing biological control: Habitat management to promote natural enemies of agricultural pests. In: Habitat
Management to Enhance Biological Control: A Concept and its Applications (Eds.: Pickett, C.H., Bugg, R.L.). UC Press, Berkeley, CA. pp.1-23.

Campbell, J.B., 1996. Introduction to Remote Sensing, $2^{\text {nd }}$ Edn. The Guilford Press, New York.

Cheeroo-Nayamuth, B., 2001. Crop modelling/ simulation: An overview. Retrieved Novemeber 11, 2012, from https://www.gov.mu/ portal/sites/ncb/ moa/farc/amas99/final.pdf\#page $=38$

Crop Information Systems - A Pilot Study in Romania, 1999. Sustainable Development Department. Food and Agriculture Organisation, U.N. http://www.fao. org/sd/EIdirect/EIre0078.htm

de Wit, C.T., Brouwer, R., Penning de Vries, F.W.T., 1970. The simulation of photosynthetic systems. In: Prediction and Measurement of Photosynthetic Productivity (Ed.: Setlik, I.). Proceeding IBP/PP Technical Meeting Trebon 1969. Pudoc, Wageningen, The Netherlands. pp.47-50.

DSSAT.net, 2013. DSSAT v4.5. Retrieved July 20, 2013, from http://dssat.net/downloads/dssat-v45

Dzotsi, K., Basso, B., Jones, J., 2013. Development, uncertainty and sensitivity analysis of the simple SALUS crop model in DSSAT. Ecol. Modell. 260, 62-76.

Goodchild, M.F., Steyaert, L.T., Parks, B.O. (Eds.), 1996. GIS and Environmental Modelling. GIS World. Fort Collins. 486p.

Graves, A. R., Hess, T., Mathews, R. B., Stephens, W., Middleton, T., 2002. Crop Simulation Models as tools in computer laboratory and classroom - based education. Nat. Resour. Life Sci. Educ. 31, 48-54.

Hammer, G.L., Sinclair, T.R., Boote, K.J., Wright, G.C., Meinke, H. and Bell, M.J., 1995. A peanut simulation model. 1. Model development and testing. Agron. J. 87, 1085-1093.

Hay, R., Porter, J., 2006. The Physiology of Crop Yield. $2^{\text {nd }}$ Edn. Blackwell Publishing, Oxford, UK.

Hilger, T. H., Herfort, J., de Barros, I., Gaiser, T., Saboya, L. M., Fallé, F., Leihner, D. E., 2000. Potential of EPIC/ALMANAC to Estimate Crop Yields under Erratic Rainfall in NE Brazil. Paper presented at the German-Brazilian Workshop on Neotropical Ecosystems - Achievements and Prospects of Cooperative Research, Hamburg.

Hoogenboom, G.J., White, J.W., Messina, C.D., 2004. From genome to crop: Integration through simulation modelling. Field Crops Res. 90, 145-163.

Hoogenboon, G., White, J.W., Jones, J.W., Boote, K.J., 1994. BEANGRO: A process oriented dry bean model with a versatile user interface. Agron. J. 86, 
182-190.

Jones, J. W., Hoogenboom, G., Porter, C. H., Boote, K. J., Batchelor, W. D., Hunt, L. A., Wilkense, P.W., Singhe, U., Gijsmana, A. J., Ritchie, J. T., 2003. The DSSAT cropping system model. Eur. J. Agron. 18, 235-265.

Jones, J.T., J. W., Tsuji, G., Hoogenboom, G., Hunt, L., Thornton, P. K., Wilkens, P., Singh, U., 1998. Decision Support System for Agrotechnology Transfer: DSSAT v3 Understanding Options for Agricultural Production. Springer, Dordrecht. pp.157-177.

Jones, J.W., Keating, B.A., Porter, C.H., 2001. Approaches to modular model development. Agric. Syst. 70, 421-443.

Kapetanaki, G., Rosenzweig, C., 1997. Impact of climate change on maize yield in central and northern Greece: A simulation study with CERESMaize. Mitigat. Adapt. Strat. Global Change. 1(3), 251-271.

Keating, B.A., Carberry, P.S., Hammer, G.L., Probert, M.E., Robertson, M.J., Holzworth, D., Huth, N.I., Hargreaves, J.N.G., Meinke, H., Hochman, Z., McLean, G., Verburg, K., Snow, V., Dimes, J.P., Silburn, M., Wang, E., Brown, S., Bristow, K.L., Asseng, S., Chapman, S., McCown, R.L., Freebairn, D.M., Smith, C.J., 2003. An overview of APSIM, a model designed for farming systems simulation. Eur. J. Agron. 18, 267-288.

Lindemann, E.R., Stöckle, C.O., Redell, D., 1987. Field testing a computer-assisted on-farm irrigation scheduling program. ASAE Paper No. 87/2560, St. Joseph, MI.

MACSUR (Modelling European Agriculture with Climate Change for Food Security) is a knowledge hub within FACCE-JPI (Joint Programming Initiative for Agriculture, Climate Change, and Food Security).

McCown, R.L., Hammer, G.L., Hargreaves, J.N.G., Holtzworth, D.P., Freebairn, D.M., 1996. APSIM: a novel software system for model development, model testing and simulation in agricultural systems research. Agric. Syst. 50, 255-271.

McKinion, J.M., Baker, D.N., Whisler, F.D., Lambert, J.R., 1989. Applications of the GOSSYM/COMAX system for cotton crop management. Agric. Syst. 31, 55-65.

McKinion, J.M., Baker, D.N., Whisler, F.D., Lambert, J.R., 1988. Application of the GOSSYM/COMAX system to cotton crop management. ASAE Paper No. 88_/7532, St. Joseph, MI.
Monteith, J.L., 2000. Agricultural meteorology: Evolution and application. Agri. For. Meteorol. 103, 5-9.

Murthy, V. R. K., 2004. Crop growth modeling and its applications in agricultural meteorology. In: Satellite Remote Sensing and GIS Applications in Agricultural Meteorology (Eds.: Sivakumar, M. K., Roy, P. S., Harmsen, K., Saha, S. K.). World Meteorological Organisation, Geneva. pp.235-261.

Nazeer, M., 2009. Simulation of maize crop under irrigated and rainfed conditions with CROPWAT model. ARPN J. Agric. Biol. Sci. 4(2), 68-73.

Nethaji Mariappan, V.E., Mohana, P., Murrugesan, C.A., 2013. Spatio-temporal assessment of air pollution from thermal stations and vehicular pollution from urban places in Tamil Nadu. Int. J. ChemTech Res. 5(1), 172-172.

Nethaji Mariappan, V.E., Pooja, V.S., Prabhu Dass Batvari, B., Indirani, R., 2017. Grape cultivation and management approaches by geospatial tools - A review. J.Adv.Res. GeoSci. Rem. Sens. 4(1\&2), 17-28.

Nethaji Mariappan, V.E., Nagamani, K., Manoharan, N., 2010. Multi-temporal land use/land cover change detection in semi urban Vellore District using Landsat TM and ETM+ Data. Int. J. Appl. Bio Eng. 4(3), 1-6.

Patricia Oteng-Darko, Yeboah, S., Addy, S. N. T., Amponsah, S., Owusu Danquah, E., 2013. Crop modeling: A tool for agricultural research - A review. J. Agric. Res. Devel. 2(1), 1-6.

Ritchie, J. T., Godwin, D. C., Otter-Nacke, S., 1985. CERES-Wheat. A Simulation Model of Wheat Growth and Development. US Department of Agriculture, Washington, D. C. pp.159-175.

Ritchie, J.T., Singh, U., Godwin, D.C., Bowen, W.T., 1998. Cereal growth, development and yield. In: Understanding Options for Agricultural Production (Tsuji, G.Y., Hoogenboom, G., Thornton, P.K.). Kluwer Academic Publishers, Dordrecht, The Netherlands. pp.79-98.

Sarkar, R., Kar, S., 2006. Evaluation of management strategies for sustainable rice-wheat cropping system, using DSSAT seasonal analysis. J. Agric. Sci. 144(5), 421-434.

Sirotenko, O.D., 1996. Mathematical models in crop bioclimatology in the former USSR (history, achievements, and prospects). Adv. Bioclimatol. 4, 125-169.

Sirotenko, O.D., Abashina, H.V., Pavlova, V.N., 1997. Sensitivity of the Russian agriculture to changes in climate, $\mathrm{CO}_{2}$, and tropospheric ozone concentrations 
and soil fertility. Clim. Change. 36, 217-232.

Smith, M., 1991. CROPWAT: Manual and Guidelines. FAO of UN, Rome.

Smith, M., 1992. CROPWAT: A Computer Program for Irrigation Planning and Management Irrigation and Drainage Paper No. 26. Food and Agriculture Organization, Rome.

Swaney, D.P., Jones, J.W., Boggess, W.G., Wilkerson, C.G., Mishoe, J.W., 1983. Real-time irrigation decision analysis using simulation. Trans. ASAE 26, 562-568.

Tsuji, G.Y., Hoogenboom, G., Thornton, P.K., 1998. Understanding Options for Agricultural Production. Springer.

Wiegand, C.L., Gerbermann, A.H., Gallo, K.P., Blad, B.L., Dusek, D., 1990. Multisite analyses of spectral-biophysical data for corn. Remote Sens. Environ. 33, 1-16.

Wilkerson, G.G., Mishoe, J.W., Jones, J.W., Boggess, W.G., Swaney, D.P., 1983. Within-season decision making for pest control in soybeans. ASAE Paper No. 83/4044, St. Joseph, MI.

Williams, J., 1990. The erosion-productivity impact calculator (EPIC) model: A case history. Philosoph. Trans. Royal Soc. London. Series B: Biol. Sci. 329(1255), 421-428.

Yunusa, I.A.M., Bellotti, W.D., Moore, A.D., Probert, M.E., Baldock, J.A., Miyan, S.M., 2004. An exploratory evaluation of APSIM to simulate growth and yield processes for winter cereals in rotation systems in South Australia. Austr. J. Exp. Agric. 44(8), 787-800.

\section{How to cite this article:}

Nagamani, K., Nethaji Mariappan, V. E., 2017. Remote sensing, GIS and crop simulation models - A review. Int. J.

Curr. Res. Biosci. Plant Biol. 4(8), 80-92. doi: https://doi.org/10.20546/ijcrbp.2017.408.011 